\title{
DO COLOURS LOOK LIKE DISPOSITIONS? REPLY TO LANGSAM AND OTHERS
}

\author{
By Alex Byrne
}

Dispositionalism about colours is the thesis that the colours are dispositions to produce certain sorts of experiences in perceivers, i.e., that colours are secondary qualities, on one use of that term. Recently dispositionalism has been under attack on the ground that 'Colours do not look like dispositions'. ${ }^{1}$ In response, Harold Langsam, in 'Why Colours Do Look Like Dispositions', The Philosophical Quarterly, 50 (2000), pp. 68-75, has argued the contrary. ${ }^{2}$

In this note I make three claims. First, neither side has made its case. Secondly, it is true, on one interpretation, that colours do not look like dispositions. Thirdly, this does not show that dispositionalism is false.

Dispositionalism (using orange as an example) may be put thus:

The property orange $=$ the disposition to look orange (to normal perceivers in normal conditions).

(As a harmless simplification, I shall largely ignore the parenthetical part, in particular the questions of how 'normal' should be interpreted and whether to rigidify on normal perceivers and conditions: for discussion of these, see Johnston.) Reductive dispositionalism results from taking (or stipulating) 'looks orange' to have some analysis that does not use colour vocabulary, perhaps in terms of Peacocke's 'sensational properties'; other versions of dispositionalism are non-reductive. ${ }^{3}$ I shall assume the relevant kind of dispositionalism is non-reductive, unless it is noted otherwise.

Some terminological regimentation is needed. To those with normal colour vision, a lemon in good light (visually) appears yellow, glossy and bulgy. Moreover,

1 See J. Dancy, 'Two Conceptions of Moral Realism', Proceedings of the Aristotelian Society, Supp. Vol. 6o (I986), pp. I67-89; P. Boghossian and J. Velleman, 'Colour as a Secondary Quality', Mind, 98 (I989), pp. 8I-IO3, repr. in A. Byrne and D. Hilbert (eds), Readings on Color, Vol. I. The Philosophy of Color (MIT Press, I997), pp. 8I-IO3; C. McGinn, The Subjective View (Oxford UP, I983), pp. I32-5, and 'Another Look at Color', Journal of Philosophy, 93 (1996), pp. 537-53; M. Johnston, 'How to Speak of the Colors', Philosophical Studies, 68 (1992), pp. 221-63, repr. in Byrne and Hilbert, pp. I37-76. McGinn seems to have been the first to claim that colours do not look like dispositions (The Subjective View, pp. I $3{ }^{2-5}$ ). However, only in his 1996 paper is this presented as a major objection.

2 John McDowell, in 'Values and Secondary Qualities', in T. Honderich (ed.), Morality and Objectivity (London: Routledge \& Kegan Paul, I985), pp. I Io-29, comes close to suggesting that colours look like dispositions.

${ }^{3}$ For the distinction, see Boghossian and Velleman, and the introduction to Byrne and Hilbert; for an example of each sort of dispositionalism, see, respectively, McGinn, The Subjective View, and C. Peacocke, 'Colour Concepts and Colour Experience', Synthese, 58 (1984), pp. $365^{-82 .}$ 
to those of moderate conceptual sophistication with common background beliefs (the kinds of perceivers relevant for present purposes), the lemon also appears to be before someone's eyes, appears to be causing a visual experience as of a yellow object, and appears disposed to look yellow. At least, all this is true on one reading of 'appears', which is the one adopted here. 'Looks' is to be read more flexibly. Sometimes the 'phenomenal use' is intended (as in the third sentence back, and the initial statement of dispositionalism); sometimes 'looks' is interchangeable with 'appears'. ${ }^{4}$ It will not be necessary to make this explicit.

What is at stake? Those who assert that 'Colours look like dispositions' hold (at least) that dispositionalism is perceptually apparent: one has (partly) visually based evidence that dispositionalism is true. The opposition, flying the banner 'Colours do not look like dispositions', hold (at least) that dispositionalism is not perceptually apparent. Therefore it would be unhappy to put an example of the sort of claim under dispute as follows:

$\mathrm{D}^{\prime}$. The property green appears to be the disposition to look green.

This is because $\left(\mathrm{D}^{\prime}\right)$ is liable to misinterpretation: if 'appears' has narrow scope with respect to 'the property green', the truth of $\left(\mathrm{D}^{\prime}\right)$ does not ensure that dispositionalism is perceptually apparent. (It may be that Ortcutt is the man in the brown hat, and that Ortcutt appears to be a spy, so that the man in the brown hat appears to be a spy; but if 'appears' has narrow scope it does not follow that it appears that the man in the brown hat is a spy.) So, instead of $\left(\mathbf{D}^{\prime}\right)$, the disputed claim is best expressed as

\section{It appears that the property green is the disposition to look green.}

This simplifies the debate. McGinn raises the question 'when an object looks red, does it look as if it has the sort of disposition that [dispositionalism] says that redness consists in?' ('Another Look', p. 539, my italics); and he proceeds to give various reasons for a negative answer. Some of these reasons evidently rely on the assumption that 'looks' is to have the 'phenomenal use' reading. And Langsam means to claim (among other things) that colours 'phenomenally' look like dispositions (he has specified this in personal correspondence). However, (D) is certainly one locus of dispute, and it is the most important.

First, Langsam's argument that colours look like dispositions. The basic objection to be developed is simple. All that can fairly be established is the following sort of claim: it appears that, typically, any object is purple iff it is disposed to look purple. And this does not imply that it appears that the property purple is the disposition to look purple.

${ }^{4}$ My use of 'appears' is very close to the 'epistemic use' of 'looks' - see F. Jackson, Perception (Cambridge UP, I977), ch. 2; he also discusses the 'phenomenal use' of 'looks'. These distinctions should not be taken to imply that 'appears' or 'looks' are correspondingly ambiguous. 
Langsam's argument is based on a specific account of perception, which now needs explaining. ${ }^{5}$ A tomato in good light looks red; in Langsam's terminology, the property red is 'presented' or, equivalently, 'represented' in the visual experience (p. 69). Further, according to Langsam, another property ('the appearance of red') is presented or represented in the visual experience; I shall call that property ' $R$ '. Langsam (pp. 7I-3) makes three important claims about $R$ :

I. $R$ is represented as a property of physical objects (the tomato, in my example)

2. $R$ is represented as a 'subjective' property - a property that is instantiated iff some object looks to have it (this, harmlessly, restricts subjective properties to the visual case, which Langsam's official account at p. 72 does not)

3. $R$ is a subjective property.

Langsam's formulation of dispositionalism, in the specific case of red, is that the property red is 'the disposition to present an appearance of red' (p. 7o). Since talk of a property's being 'presented' can be translated by 'looks', this may be recast as 'The property red is the disposition to look to have $R$ '. But from (3) it follows that, necessarily, something has $R$ iff it looks to have $R$, and therefore there is at best a hair's breadth between Langsam's formulation of dispositionalism and this simpler one: the property red is the disposition to have $R$. And in fact the simpler formulation fits better with Langsam's repeated claim that 'colour appearances' are the 'manifestations' of the relevant dispositions (see pp. 70, 71, 73), and with his overall argument. Accordingly I shall conduct the discussion using the simpler formulation. (Both formulations are versions of reductive dispositionalism.)

What is $R$ is supposed to be? Some sense-datum theorists hold that physical objects, not sense-data, are coloured. Sense-data, on this view, have other properties that can be perspicuously labelled using Peacocke's 'primed' notation: thus a tomato before the eyes will typically produce a red' sense-datum. ${ }^{6}$ According to Langsam, these theorists have misdescribed red'ness: it is not a property of a sense-datum, and is in fact none other than $R$ (see pp. 70-1, esp. fn. 5).

Now Langsam does not provide a positive case for the existence of $R$, as he conceives it. (Perhaps one can be found by adapting the considerations in favour of red'ness supplied by Peacocke and by Boghossian and Velleman.) Fortunately, though, this complicated issue can be sidestepped: even if Langsam is right about $R$, his argument can still be disarmed.

Langsam takes (I), (2) and (3) to be part of the reasons for making the following crucial claim. $R$ is represented 'in an experience as the way some objective property of [an] object appears to the subject of the experience' (p. 73):

So, for example, my visual experience presents the appearance of red [i.e., $R$ ] as a (subjective) property of the [tomato] only by presenting it as the way that a certain objective property of the [tomato] appears. And what is the objective property in

${ }^{5}$ See Langsam, 'Why Pains are Mental Objects', fournal of Philosophy, 92 (1995), pp. 303-13, and 'The Theory of Appearing Defended', Philosophical Studies, 87 (1997), pp. 33-59.

${ }^{6}$ See Peacocke, Sense and Content (Oxford UP, 1983), chs I-2, and 'Colour Concepts and Colour Experience'. 
question? The redness of the [tomato], of course.... visual experiences present colour appearances [properties like $R$ ] as the way colours appear. And they present colours as those objective properties of the object's surface that present themselves to the subject via certain kinds of perceptual appearances (i.e., colour appearances).

Langsam's terminology is a little unfortunate. For the claim that visual experience presents $R$ as 'the way redness appears' suggests that redness looks to have the property $R$. But this is not what Langsam means (he is quite clear elsewhere that the things that look to have $R$ are objects like tomatoes, not properties). Instead he means something like this:

4. When one sees a red object in normal conditions, it appears that the object's having $R$ is an effect of the object's being red.

The argument from this intermediate result to the promised conclusion, that colours look like dispositions, is as follows (pp. 73-4):

What are the nature of these objective properties [like redness]? Not surprisingly, they just are the properties of being disposed to present certain kinds of colour appearances in certain circumstances: they are dispositional properties. So we may say that colour appearances $[$ e.g., $R]$ are presented as properties of physical objects in virtue of being presented as the way that certain objective properties of physical objects (the colours) appear, that is, in virtue of being presented as manifestations of certain dispositional properties of physical objects.... Colours do look like dispositions, for the objective properties that are presented in colour experience are presented as dispositional properties, dispositions to present certain kinds of appearances.

As is obvious, Langsam's conclusion is not just that colours look like 'dispositions to present certain kinds of appearances': it is also that colours are such dispositions. But this does not introduce any new consideration, because Langsam's only argument for it is that this is the way colours appear. If he is wrong to claim that colours look like dispositions, then his case for colours' being dispositions collapses.

The main conclusion of the quoted passage, that colours look like dispositions, may be put (using red as an example) as follows:

5. It appears that the property red is the disposition to have $R$.

The trouble is that (5) is not supported by (4) and any other premises that Langsam might be granted for the sake of the argument. This can be shown by exhibiting these premises. From (2) above, it appears that an object has $R$ iff it looks to have $R$. Putting this together with (4), it seems reasonable to conclude

6. When one sees a red object in normal conditions, it appears disposed to have $R$ (specifically, disposed to have $R$ when being perceived by a normal perceiver in normal circumstances).

The following may also be granted:

7. When one sees a red object in normal conditions, it appears red. 
If (6) and (7) are true, then by seeing a wide variety of coloured objects one may amass evidence that being red and being disposed to have $R$ typically go together:

8. It appears that, typically, any object is red iff it is disposed to have $R$.

However, it would be rash to remove 'typically'. Imagine a strange object that is not red, yet is disposed to have $R$. It would have $R$ in normal conditions, and so would (misleadingly) appear red in normal conditions. One's visually based evidence surely does not exclude the possibility that there are any such objects. (Moreover, even if 'typically' were removed, the result would still not be strong enough, since actual coextensiveness is insufficient for property identity.)

This basic point can be made without presupposing Langsam's theoretical apparatus. When one looks at a tomato in normal conditions, one has (partly) visually based evidence that the tomato is disposed to look red (to normal perceivers in normal conditions). More generally:

9. When one sees a red object in normal conditions, it appears disposed to look red.

For the same reason as before, (7) and (9) do not show that it appears that the property red is the disposition to look red. Rather, these premises only support

IO. It appears that, typically, any object is red iff it is disposed to look red.

Again it would be rash to remove 'typically' (not that this would help much). For the appearances do not preclude, for example, the existence of strange red objects that are not disposed to look red. (Of course, one might claim that any counter-examples to 'Any object is red iff it is disposed to look red' are impossible a priori. But that would render the debate about whether colours look like dispositions entirely otiose.)

Finally, there is a quicker ('Berkeleyan') way of raising suspicions: this style of argument works equally well, or equally badly, for dispositionalism about shape.

\section{II}

Since it is unobvious that colours look like dispositions, some argument is required, and the moral of the last section is that none seems to be forthcoming. Therefore we may join the majority, and affirm the negation of $(\mathrm{D})$ :

ND. It does not appear that the property green is the disposition to look green.

However, some go further, and claim that colours look as if they are not dispositions:

$\mathrm{ND}+$. It appears that the property green is not the disposition to look green.

For instance, Dancy (p. I8I): 'colour ... seems to me at least to be stubbornly nondispositional'. (ND+) is not plausible. The only real defence of it is offered by McGinn ('Another Look', p. 542):

when we see an object as red, we see it as having a simple, monadic, local property of the object's surface. The colour is perceived as intrinsic to the object, in much the 
same way as shape and size are perceived as intrinsic. No relation to perceivers enters into how the colour appears; the colour is perceived as wholly on the object, not as somehow straddling the gap between it and the perceiver.

Here McGinn makes some claims about ways colours do not appear and five claims about the ways they do appear. Only the latter are relevant to (ND+). McGinn says that the colours appear 'simple', 'monadic', 'local', and 'intrinsic'. Further, 'the colour is perceived as wholly on the object'. The implication is that if any of these appearances is veridical, then colours are not dispositions.

Although McGinn is not explicit about his terminology, the context clearly indicates that the last four claims are intended to be equivalent, and to amount to this: colours appear non-relational. That is, they appear not to be relational, where a property is relational iff it is identical to the property of standing in $R$ to $x$, for some replacement for the schematic ' $R$ ' and ' $x$ '; thus dispositions are relational. Two points are worth noting: first, this account (a reconstruction of what McGinn apparently has in mind) threatens to have the unwanted consequence that every property is relational (we can replace ' $R$ ' by 'the instantiation relation' and ' $x$ ' by a noun phrase rigidly denoting the property itself). The way out is either to individuate properties more finely than by necessary co-extensiveness (this is McGinn's view), or else to restrict severely the allowable substituends for ' $R$ ' and ' $x$ '. Secondly, McGinn's use of 'intrinsic' for 'non-relational' is potentially confusing, because non-relationality should be distinguished from intrinsicness in the Kim-Lewis sense. ${ }^{7}$

Since McGinn gives much more emphasis to the apparent non-relationality of the colours than to their apparent 'simplicity', the latter may be set aside. So when boiled down to its essentials, McGinn's argument largely evaporates: for surely the non-relationality of the colours is no more evident or uncontroversial than their non-dispositionality. And - here I can only speak for myself - the colours do not appear non-relational to me.

Although the more modest (ND) is correct, the arguments that are given for it are mistaken, and it is useful to see why. Here is Boghossian and Velleman's explanation (p. 85) of why it is not the case that colours look like dispositions:

When one enters a dark room and switches on a light, the colours of surrounding objects look as if they have been revealed, not as if they have been activated. That is, the dispelling of darkness looks like the drawing of a curtain from the colours of the objects no less than from the objects themselves. If colours looked like dispositions, however, then they would seem to come on when illuminated, just as a lamp comes on when its switch is flipped. Turning on the light would seem, simultaneously, like turning on the colours; or perhaps it would seem like waking up the colours, just as it is seen to startle the cat. Conversely, when the light was extinguished, the colours would not look as if they were being concealed or shrouded in the surrounding darkness; rather, they would look as if they were becoming dormant, like the cat returning to sleep. But colours do not look like that; or not, at least, to us.

${ }^{7}$ For this sense, see, for example, R. Langton and D. Lewis, 'Defining "Intrinsic", Philosophy and Phenomenological Research, $5^{8}$ (1998), pp. 333-45. 
This complaint is partly endorsed by Johnston (p. I4I) - only partly, because he thinks that some ('unsteady') colours do look like dispositions.

In fact, pace Boghossian and Velleman, colours do 'seem to come on' when illuminated, reds and greens 'coming on' before yellows and blues, at any rate if the illumination is increased very slowly. ${ }^{8}$ But that is an aside. The important point is that these claims, about how it could have turned out that colours look like dispositions, are incorrect.

Boghossian and Velleman's idea seems to be that if the colours of objects appeared to 'come on' when illuminated, it would appear that the manifestation of the disposition was occurring, just as it appears that the manifestation of fragility occurs when the wine glass hits the floor. Colours, in such a counterfactual circumstance, would then appear to be dispositions (to look coloured). So colours do not actually appear to be dispositions, because they do not appear the way the colours appear in the counterfactual circumstance.

However, this line of thought is doubly wrong. First, although it is true in the counterfactual circumstance that it appears that the manifestation of a disposition is occurring, the trouble is that it is the wrong disposition. Secondly, granted that the manifestation of the right disposition does appear to occur, this would not show that colours look like dispositions. I shall take these points in turn.

Imagine that colours noticeably 'come on' when illuminated, and that a ripe tomato is before the eyes just as the lights go up. What is the most obvious difference between this counterfactual situation and an actual case of illuminating a tomato? Surely this: in the counterfactual situation, the tomato appears to become red. Thus, in the counterfactual situation, unlike the actual situation, the tomato appears disposed to be red (when illuminated), and it appears that the manifestation of this disposition is occurring. But this is the wrong disposition: the relevant disposition is the disposition to look red, not the disposition to be red.

As to the second point, it was noted in the previous section that as things actually are, when one looks at a tomato, the tomato appears to have the disposition to look red, and it appears that the manifestation of this disposition is occurring. So the supposition that colours 'come on' when illuminated is simply a distraction; it is better to concentrate on the actual case. (In the counterfactual situation the tomato appears to have the disposition to look red only when it is seen. The counterfactual situation is thus akin to examples of 'finkish' dispositions.) And, again as noted in the previous section, the fact that a tomato appears to have the disposition to look red does nothing at all to show that it appears that this disposition and the property red are identical.

Hence Boghossian and Velleman, and Johnston, were right after all to claim that colours do not look like dispositions, albeit for the wrong reasons. One cannot tell just by looking that dispositionalism is true, because, on the most optimistic scenario, the evidence of one's eyes is merely that the colours and the dispositions to look coloured typically go together.

${ }^{8}$ This can easily be verified using a dimmer: see R. Boynton, Human Color Vision (New York: Holt, Rinehart \& Winston, I979), p. 40. The change in perceived hue with illumination is known as the Bezold-Brücke hue shift. 
This story has one loose end, which needs to be tied. Boghossian and Velleman evidently think that (ND) is a strong objection to dispositionalism, although they do not explain why. (As mentioned above, McGinn holds (ND+), but he also seems to think that (ND) alone makes trouble for dispositionalism: see his p. 538.) This is puzzling. After all, it is not the case that samples of alcohol look like samples of $\mathrm{CH}_{3} \mathrm{CH}_{2} \mathrm{OH}$, but that is hardly an objection to their identification as such.

The missing premise that turns (ND) into an objection to dispositionalism is a thesis Johnston calls Revelation, which in the case of canary yellow is 'The intrinsic nature of canary yellow is fully revealed by a standard visual experience as of a canary yellow thing'. ${ }^{9}$ Visual experience, according to Revelation, provides one with total information about the nature of the colours. ${ }^{10}$ It can usefully be split into two parts. First, if the proposition that $p$ concerns the nature of the colours and it appears that $p$, then it is true that $p$ (Infallibility). Secondly, if the proposition that $p$ concerns the nature of the colours and it is true, then it appears that $p$ (Self-Intimation). 'Concerns the nature of the colours' does not need formal definition here: it is sufficient to note that this expression is intended to apply to the proposition that the property blue is the disposition to look blue, or is such and such a physical property.

Now if Self-Intimation, is true, then dispositionalism is straightforwardly false, because it is not the case that colours look like dispositions. In fact, if Self-Intimation is true, no interesting claim about the nature of the colours is right. The property blue cannot be a physical property, or even a property informatively characterized in the vocabulary of some yet to be formulated non-physical science, because these claims do not appear to be true. Self-Intimation is thus a powerful weapon indeed.

There is something attractive about Revelation. But when it is parcelled out into Infallibility and Self-Intimation, only the first part of the package is seriously tempting. It is not implausible to think that if the proposition that $p$ concerns the nature of the colours (to borrow Johnston's example, that canary yellow is not a shade of blue) and if it appears that $p$, then it is true that $p$. However, any Revelation-based argument against dispositionalism needs not Infallibility but its much more dubious converse.

Dispositionalism, then, is not perceptually apparent. If the doctrine of Revelation were correct, then the falsity of dispositionalism would follow. But the only defensible part of Revelation is Infallibility, and that leaves dispositionalism untouched. If dispositionalism is to be rejected, it must be for other reasons. ${ }^{11}$

\section{Massachusetts Institute of Technology}

${ }^{9}$ Johnston, p. I38. He helpfully suggests (p. I69, fn. 6) that Boghossian and Velleman may be tacitly appealing to something like Revelation. Cf. McGinn, 'Another Look', p. 538, fn. 3 .

${ }^{10}$ See D. Hilbert, Color and Color Perception (Stanford: CSLI, I987), p. 37.

11 See Boghossian and Velleman; Johnston, 'Are Manifest Qualities Response-Dependent?', Monist, 8I (1998), pp. 3-43; B. Stroud, The Quest for Reality (Oxford UP, 200o), ch. 6.

Thanks to Susanna Siegel and referees for The Philosophical Quarterly for comments; I am especially grateful to Harold Langsam for very helpful correspondence. 